\title{
The Immunization and Arbitrage Difficult to Match the Risk
}

\author{
Zhang $\operatorname{Yan}^{1}$ Yu Bin ${ }^{2}$ \\ ${ }^{1}$ International Business Faculty, Beijing Normal University, zhuhai, China 519087 \\ ${ }^{2}$ Academy of Marxism Chinese Academy of Social Sciences Beijing 100732 \\ zylzxz@sina.com
}

\begin{abstract}
The problem of greatest importance in the financial investment is the existence of lots of risks primarily resulting from changes in interest rates and yields. It is stated in the immunization theory and the arbitrage pricing theory that the elimination of risks and further the obtaining of arbitrage can be realized by matching risks of assets with those of obligations, and it also seems possible to determine the theoretical price of financial assets through the idea of no-arbitrage. In this paper, the author proves the shortcoming of the the immunization theory by the employment of a mathematical example and a practical case, and points out that the conclusions of the arbitrage pricing theory are based on an assumption of an impossible scenario. It is concluded finally it is impossible as well as insignificant to eliminate investment risks in the decentralized decision-making market economy.
\end{abstract}

Index Terms - Risk Immunization Arbitrage Market economy

\section{Introduction}

It is well known that the problem of greatest importance in the financial investment is the existence of lots of risks primarily resulting from changes in interest rates and yields. Naturally, The risks of assets and obligations are matched for the purpose of eliminating the risks and further getting arbitrage. Even if the arbitrage space will disappear due to the market competition, it still seems possible to apply the idea of no-arbitrage to determine the theoretical price of financial assets. Immunization theory and arbitrage pricing theory are the outcome of this idea. However, is it really easy to match or eliminate the risks?

\section{II . The problem in the immunization}

The change of the interest rates is inevitable. With the changes in interest rate, the value of financial assets and obligations changes respondingly. Western financial experts think there is a procedure termed immunization which can be applied to structure a bond portfolio to protect against interest rate risk, because it "immunizes" the portfolio value against interest rate changes. ${ }^{[1] \mathrm{P} 62 \sim 63}$

In the immunization therom, if the duration of the the porfolio matches that of the obligation stream, then the cash value of the porfolio and the present value of the obligation srtream will respond indentically to first order to a change in yield. Specifically, if yields increase, the present value of the asset portfolio will derease, but the present value of the obligation will decrease by appoxmately the same amount, so the value of the porfolio will still be adquate to cove the obligation. ${ }^{[1] \mathrm{P} 63}$

Before explaining it through an example, we state the definition of the Duration first.

Suppose a financial instrument makes payments $m$ times per year, with the payment in period $\mathrm{k}$ being $\mathrm{c}_{\mathrm{k}}$, and there are $\mathrm{n}$ periods remaining, The Macaulay duration $\mathrm{D}$ is defined as

$$
D=\frac{\sum_{k=1}^{n}(k / m) c_{k} /[1+(\lambda / m)]^{k}}{P V}
$$

Where $\lambda$ is the yield to maturity and $P V=\sum_{k=1}^{n} c_{k} /[1+(\lambda / m)]^{k}$.

Duration of a portfolio: Suppose there are $\mathrm{m}$ fixedincome securities with prices and duration of $\mathrm{P}_{\mathrm{i}}$ and $\mathrm{D}_{\mathrm{i}}$, respectively, $\mathrm{i}=1,2, \ldots, \mathrm{m}$, all computed at a common yield. The portfolio consisting of the aggregate of theses securities has price $\mathrm{P}$ and duration $\mathrm{D}$, given by

$$
\begin{aligned}
& \mathrm{P}=\mathrm{P}_{1}+\mathrm{P}_{2}+\ldots+\mathrm{P}_{\mathrm{m}} \\
& \mathrm{D}=\mathrm{w}_{1} \mathrm{D}_{1}+\mathrm{w}_{2} \mathrm{D}_{2}+\ldots+\mathrm{w}_{\mathrm{m}} \mathrm{D}_{\mathrm{m}}
\end{aligned}
$$

Where $\mathrm{w}_{\mathrm{i}}=\mathrm{P}_{\mathrm{i}} / \sum_{i=1}^{m} P_{i}, \mathrm{i}=1,2, \ldots, \mathrm{m}$.

[Example]The $\mathrm{X}$ corporation has an obligation to pay $\$ 1$ million in 10 years. It wishes to invest money now that will be suufficient to meet this obligation. The $\mathrm{X}$ corporation is planning to select from the three corporate bonds shown in Table 1:

TABLE $1 \quad$ Bond Choices [1]P82

\begin{tabular}{|c|c|c|c|c|c|}
\hline & Rate & Maturity & Price & Yield & Duration \\
\hline Bond 1 & $6 \%$ & $30 \mathrm{yrs}$ & 69.04 & $9 \%$ & 11.44 \\
\hline Bond 2 & $11 \%$ & $10 \mathrm{yrs}$ & 113.01 & $9 \%$ & 6.54 \\
\hline Bond 3 & $9 \%$ & $20 \mathrm{yrs}$ & 100 & $9 \%$ & 9.61 \\
\hline
\end{tabular}

The duration of the obligation is 10 years, and there is no way to attain that with a weighted average of D2 and D3 using positive weights. Therefore the $\mathrm{X}$ corporation decides to use the bonds 1 and 2 . 
The present value of the obligation is computed at $9 \%$ interest payable half-yearly, this is $\mathrm{PV}=\$ 414642.86$. The immunized porfolio is found by solving the two equations:

$$
\left\{\begin{array}{c}
V_{1}+V_{2}=P V \\
D_{1} V_{1}+D_{2} V_{2}=10 P V
\end{array}\right.
$$

The first equation states that the total value of the porfolio must equal the total present value of the obligation. The second states that the duration of the portfolio must equal the duration (10 years ) of the obligation.

The solution to these equations is $\mathrm{V}_{1}=\$ 292788.73$ and $\mathrm{V}_{2}=\$ 121854.27$. The number of bonds to be purchased is then found by dividing each value by the respective bond price. (we assume a face value of $\$ 100$.) These numbers are then rounded to integers to define the porfolio.

Thus we can obtain the following immunization results $^{[1] \mathrm{P} 83}$ :

TABLE 2 Immunization Results

\begin{tabular}{|c|c|c|c|}
\hline & \multicolumn{3}{|c|}{ Percent yield } \\
\hline & 9 & 8 & 10 \\
\hline Bond1 & & & \\
Price & 69.04 & 77.38 & 62.14 \\
Shares & 4241 & 4241 & 4241 \\
Value & 292798.64 & 328168.58 & 263535.74 \\
\hline Bond 2 & & & \\
Price & 113.01 & 120.39 & 106.23 \\
Shares & 1078 & 1078 & 1078 \\
Value & 121824.78 & 129780.42 & 114515.94 \\
\hline Obilgation & 414642.86 & 456386.95 & 376889.48 \\
Value & & 1562.05 & 1162.20 \\
\hline Surplus & -19.44 & & \\
\hline
\end{tabular}

From the table above, even if the yield changes, the absolute vaule of the difference between the value of the porfolio and value of the obligation is no more than $4 \%$, approximately near to zero. If the yield changes immediately after purchase of the porfolio, Theoretically, the new present value of the portfolio still will approximately match the new present value of the future obligation. But, if the yield does change, the new portfolio will not be immunized at the new rate. It is therefore desirable to rebalance, or re immunize the portfolio from time to time.

In the computing above, Despite the same durations, the portfolio differs from obligation in their maturities. The idea of computing the present value is a kind of method of computing backward. However, the maturity and payoff of obligation happen in the future. we will explore what will happen by computing forward to the future. In the table below, we assume that the obligation is issued by compound interest rate of $9 \%$ payable half-yearly. The bonds are to be redeemed at par.
TABLE 3 The Asset and Obligation in 10 years

\begin{tabular}{|c|c|c|c|}
\hline & \multicolumn{3}{|c|}{ Percent yield } \\
\hline & 9 & 8 & 10 \\
\hline $\begin{array}{c}\text { Bond } 1 \\
\text { Price } \\
\text { Shares } \\
\text { Value } \\
\text { Interest gains }\end{array}$ & $\begin{array}{c}72.40 \\
4241 \\
307048.40 \\
399138.61\end{array}$ & $\begin{array}{c}80.21 \\
4241 \\
340170.61 \\
378866.49\end{array}$ & $\begin{array}{c}65.68 \\
4241 \\
278548.88 \\
420698.13\end{array}$ \\
\hline $\begin{array}{c}\text { Bond } 2 \\
\text { Price } \\
\text { Shares } \\
\text { Value } \\
\text { Interest gains }\end{array}$ & $\begin{array}{c}100 \\
1078 \\
107800 \\
186001.17\end{array}$ & $\begin{array}{c}100 \\
1078 \\
107800 \\
176554.23\end{array}$ & $\begin{array}{c}100 \\
1078 \\
107800 \\
196048.04\end{array}$ \\
\hline $\begin{array}{l}\text { Value of the } \\
\text { obligation }\end{array}$ & $1,000,000$ & $1,000,000$ & $1,000,000$ \\
\hline Surplus & -11.82 & 3391.33 & 3095.05 \\
\hline
\end{tabular}

From the table above, the immunization provides a very good protection against changes in yield. Even if the yield changes immediately after purchase of the porfolio, the value of the assets exceeds that of the obligation, consequently debt free.

However, the key problem is that the yield changes unexpectedly all the time. From the Table 3, we can see, at any point of time the funds in the portfolio used for paying off the obligation consist of three parts: the compounding accumulation value of the interest, the face value of maturity bond at that point of time, the value of non maturity bond. Thereinto, the face value of the maturity bond is fixed, while either the compounding accumulation value of the interest, or the the value of non maturity bond is related to the change of the yield, the former affected before the change and the latter after the change. In the Table 2 and 3, the yields before and after the $10^{\text {th }}$ year are the identical, so it is immunized. If the yield changes in different periods of time, the result will change a lot.

For example, if the yield changes to $8 \%$ payable halfyearly immediately after purchase of the porfolio, and changes to $10 \%$ ten years later. The result is listed in Table 4 .

TABLE 4 The surplus at the 10th year

\begin{tabular}{|c|c|}
\hline & At the $10^{\text {th }}$ year \\
\hline Bond 1 & 65.68 \\
Price & 4241 \\
Shares & 278548.88 \\
Value & 378866.49 \\
Interest gains & 100 \\
\hline Bond 2 & 1078 \\
Price & 107800 \\
Shares & 176554.23 \\
Value & $1,000,000$ \\
\hline Interest gains & $-58,230.40$ \\
\hline Value of the obligation & \\
\hline Surplus &
\end{tabular}


In the case of Table 4, a surplus of $-58,230.40$, almost $6 \%$ of the value of the obligation, can never be ignored.

It is also can be illustrated by a practical case, which happened in the OrangeCounty California, USA, at the end of 1994. In October 1993, Robert·Hilton, the fiscal investment fund manager, purchased the 5 years U.S. Treasury bonds with a face value of $\$ 124.80$ million by a short-term loan at a rate of $3.31 \%$ per half year. The effect yield is $4.61 \%$. If the term structure of the rate had remained the same during the holding period, the holder would have got $1.3 \%$ profit from the investment, i.e. $\$ 1.60$ million. But the fact is that at the end of the 1994, the rate of loan increased to $6 \%$, the anticipated profit disappeared with a loss of $\$ 1.50$ million.

On the surface, Hilton failed because he didn't take the immunization. However, on the one hand, entire immunization means complete absence of profit, if Hilton used the 6 monthes loan to buy 6 monthes U.S Treasury bond, how could he gain the profits? On the other hand, if the real rate changed by just $1 \%$ as shown in the text book, Hilton could have profits by at least $0.3 \%$, instead of the loss.

In fact, in the process of computing forward shown in table 3, the gains of the interest are also computed on the premise of that the future interest is fixed, or changes expectedly as designed. On this point, theorists are of little difference from bankrupted Hilton.

\section{III . The Problem in Arbitrage Pricing Theory (APT)}

Simple APT ${ }^{[1] \mathrm{P} 209}$ : Suppose that there are $\mathrm{n}$ assets whose rates of return are govened by $\mathrm{m}(\mathrm{m}<\mathrm{n})$ factors according to the equation:

$$
r_{i}=a_{i}+\sum_{j=1}^{m} b_{i j} f_{j} \quad(\mathrm{i}=1,2, \ldots, \mathrm{n})
$$

Then there are constants $\lambda_{0}, \lambda_{1}, \ldots, \lambda_{\mathrm{m}}$, such that $\bar{r}_{i}=\lambda_{0}+\sum_{j=1}^{m} b_{i j} \lambda_{j} \quad(\mathrm{i}=1,2, \ldots, \mathrm{n})$.

To explain the concept, we consider a special case $^{[1] \mathrm{P} 207 \sim 208}$ of one - factor model for two assets $\mathrm{i}$ and $\mathrm{j}$, which is: $r_{i}=a_{i}+b_{j} f, r_{j}=a_{j}+b_{j} f$

where $f$ is a random variable, standing for the random single factor.

The only requirement in the selection is that $b_{i} \neq b_{j}$. Now we form a portfolio with weighs $w_{i}=w$ and $w_{j}=1-w$. The rate of return of this portfolio is :

$$
r=w a_{i}+(1-w) a_{j}+\left[w b_{i}+(1-w) b_{j}\right] f
$$

We shall select $w$ so that the coefficient of $f$ in this equation is zero, specifically, we select $w=b_{j} /\left(b_{j}-b_{i}\right)$. This yields a rate of return of $r=w a_{i}+(1-w) a_{j}=\frac{a_{i} b_{j}}{b_{j}-b_{i}}+\frac{a_{j} b_{i}}{b_{i}-b_{j}}$.

This special portfolio is risk free because the equation for $r$ contains no random element. The risk-free assets must have tha same rate of return, otherwise there would be an arbitrage opportunity, so we denote this rate by $\lambda_{0}$, we find: $\frac{a_{i} b_{j}}{b_{j}-b_{i}}+\frac{a_{j} b_{i}}{b_{i}-b_{j}}=\lambda_{0}$.

Therefore: $\frac{a_{j}-\lambda_{0}}{b_{j}}=\frac{a_{i}-\lambda_{0}}{b_{i}}$.

This is a general relation that must hold for all $i$ and $j$, thus $\frac{a_{j}-\lambda_{0}}{b_{j}}=c$.

It holds for all $i$ for some constant $c$. This shows explicitly that the value of $a_{i}$ and $b_{i}$ are not independent. Indeed $a_{i}=\lambda_{0}+b_{i} c$.

$$
\text { So, } \bar{r}_{i}=a_{i}+b_{i} \bar{f}=\lambda_{0}+b_{i}(c+\bar{f})=\lambda_{0}+b_{i} \lambda_{1} \text {. }
$$

Where the constant $\lambda_{1}=c+\bar{f}$. Therefore, once the constants $\lambda_{0}$ and $\lambda_{1}$ are known, the expected return of an asset is determined entirely by the factor $b_{i}$ ( Since $a_{i}$ must follow $\left.b_{i}\right)^{[1] \mathrm{P} 209}$.

However, from the simplified example above, we can see there is a big problem in the Arbitrage Pricing Theory (APT). Indeed, here it is to say that $a_{i}$ must follow $b_{i}$, not as good as to say that the asset $j$ must follow asset $i$, because of the coefficient of correlation of the two assets ( when $b_{i} b_{j} \neq 0$.)

$$
\rho_{i j}=\frac{b_{i} b_{j}}{\left|b_{i} b_{j}\right|}= \begin{cases}1 & \text { if } b_{i} b_{j}>0 \\ -1 & \text { if } b_{i} b_{j}<0\end{cases}
$$

That is to say, there is a perfect linear relationship ( say, perfect negative correlation or perfect positive correlation ) between the two assets.

Therefore, the APT makes a same mistake as that in the Capitical Structure Irrelevance Theory ${ }^{[2]}$, i.e. assumption of an impossible scenario and conclusions from the scenario. Even if we take for grant the special assumption of APT that there exist many kinds of the securitis, there are factors as many as the securities, i.e. $m$ is not less than $n$. just as there are no two indentical leaves in the world, by the same taken, there are no indentical combinations of the leaves. In fact, the most critical assumption in APT is $m<n$. Under this assumption, by finding a portfolio of the two assets which are completely linear dependent via the elimination method in linear algebra, we can consequently get a portfolio of risk-free, which satisfies the numerical equation. There is a similar argument that a person can lift himself on the premise that there are two "yous". One of you can surely lift the other "you", but the problem is there is only one "you".

In addition, even if we approbate the equation above, we can not say $a_{i}$ must follow $b_{i}$. Obviously, if $c=0$, no matter what is the value of $b_{i}$ may be, ai always equals the risk-free yield $\lambda_{0}$, how can we conclude that $a_{i}$ must follow $b_{i}$ ? Furthermore, the 
factors that will determine the value of $c$ are still unsolved. If the value of $c$ is not determined, it is impossible to determine the value of $\lambda_{1}$. If the value of $\lambda_{1}$ is unkown, the APT is of meaningless and useless even if it is based on the impossible scenario.

In short, the investment is always accompanied with the risk, specially the investment with a liability. It is impossible to eliminate the investment risk in the decentralized decisionmaking market economy. Even if the risk can be eliminated, the consequent is the fewer revenue. What is more serious is the attempt to eliminate the investment risk based on a fallacious theory will expand the risk of the investment.

\section{References}

[1] David G . Luenberger, Investment Science, New York Oxford: Oxford university press 1998

[2] Yu Bin , The shame of the Nobel Prize in Economics----a total negation of the Capital Structure Irrelevance Theory (CHINESE VERSION) Beijing: China Business Press, 2001, P47 